\title{
Native type II collagen-induced arthritis in the rat. I. Incidence and humoral response to collagen
}

\author{
K. MORGAN, R. B. CLAGUE, MARY J. SHAW, AND P. J. L. HOLT \\ From the Department of Rheumatology, University of Manchester Medical School, Stopford Building, Oxford \\ Road, Manchester M13 9PT
}

SUMMARY An acute inflammatory arthritis has been induced in $76 \%$ of rats injected intradermally with native bovine type II collagen emulsified in Freund's complete (CFA) or incomplete (ICFA) adjuvant. The arthritis became chronic in 14 out of 31 rats, and ear and tail lesions were noted in some rats. No arthritis was induced by native type I collagen, denatured type II collagen, rabbit IgG, or buffer alone injected intradermally with adjuvant. Using a solid-phase radioimmunoassay for serum antibodies we have shown that IgM and IgG levels to native bovine type II collagen were significantly higher in arthritic than nonarthritic rats. Antiglobulin antibody levels were not raised in arthritic rats. Equivalent antibody levels to native type II collagen were obtained whether this antigen was emulsified in ICFA or CFA. However, native type I collagen produced high antibody levels only when emulsified in CFA, indicating a difference in the immunogenicity of these collagens. These studies suggest that native type II collagen possesses arthritogenic properties in the rat and that humoral immunity may play a role in the induction of this arthritis.

The induction of a chronic inflammatory arthritis in the rat by the intradermal injection of human, chick, or rat collagen obtained from articular cartilage and emulsified in either Freund's complete (CFA) or incomplete (ICFA) adjuvant has recently been described by Trentham et al. (1977). The incidence of arthritis was approximately $40 \%$ in the rat strains tested and mainly affected the hind limbs.

Both cellular and humoral immune responses to native type II collagen can be detected in these rats, and there appears to be some correlation between higher levels of sensitivity to the collagen and the presence of arthritis (Trentham et al., 1978).

We here describe the induction and clinical course of arthritis in the rat using a different heterologous native type II collagen (bovine) and the humoral responses in arthritic and nonarthritic rats.

\section{Materials and methods}

Rats. Outbred female Sprague-Dawley rats (150$250 \mathrm{~g}$ ) from the Manchester Medical School Closed Colony were used. They were given food and water ad libitum.

Accepted for publication 30 April 1979

Correspondence to Dr K. Morgan.
Collagen. Native bovine type II collagen was extracted from articular cartilage by pepsin solubilisation after previous treatment with $2 \mathrm{M}$ magnesium chloride (Trelsted et al., 1977). Acid-soluble native bovine type I collagen was extracted from fetal calf skin and purified by the method of Jackson and Cleary (1967). Both collagens were lyophilised and stored at $-20^{\circ} \mathrm{C}$ until used.

The collagen types appeared pure on polyacrylamide gel electrophoresis, and the type II collagen was negative for uronic acid, suggesting that there was no proteoglycan contamination (Bitter and Muir, 1962).

The type II collagen was dissolved in $0.45 \mathrm{M} \mathrm{Na}$ $\mathrm{C1} / 0.02 \mathrm{M}$ Tris buffer, $\mathrm{pH} 7 \cdot 4$, at a concentration of $1 \mathrm{mg} / \mathrm{ml}$ before use. Type I collagen was dissolved in $0.1 \mathrm{M}$ acetic acid at the same concentration and dialysed extensively into $0.45 \mathrm{M} \mathrm{Na} \mathrm{C1/0.02} \mathrm{M}$ Tris buffer. Bovine type II collagen was denatured by heating at $45^{\circ} \mathrm{C}$ for 20 minutes shortly before use.

Rabbit IgG. Rabbit IgG was isolated by DEAEcellulose chromatography (Hudson and Hay, 1976).

Adjuvants. All antigens were emulsified in either Freund's complete or incomplete adjuvant (Miles Laboratories Ltd.) in a ratio of 1:1.

Injection of rats. Rats were injected intradermally on the back at several sites with $1 \mathrm{ml}$ of emulsion containing $500 \mu \mathrm{g}$ of collagen or rabbit IgG. Booster 
doses of $500 \mu \mathrm{g}$ of collagen alone without adjuvant (or rabbit IgG alone) were given intraperitoneally on day 21 , except for rats immunised with native bovine type I collagen, where no boost was given.

CFA and ICFA were also emulsified with $0.45 \mathrm{M}$ $\mathrm{Na} \mathrm{C1/0.02} \mathrm{M}$ Tris buffer alone in a $1: 1$ ratio and injected as above but without subsequent boosting.

Rats were examined on alternate days throughout the experiment for evidence of arthritis or nonarticular lesions.

Serum collection. Blood was collected from rats at intervals under light ether anaesthesia by cardiac puncture. After clotting, the blood was centrifuged at $1500 \mathrm{~g}$ for 7 minutes, and the serum was removed and stored at $-20^{\circ} \mathrm{C}$.

Radioimmunoassay. Class specific IgG and IgM antibodies to collagen were measured by a solidphase double antibody radioimmunoassay (Clague et al., 1979a). Briefly, $2 \mu \mathrm{l}$ of serum was incubated in duplicate with $500 \mu \mathrm{l}$ of $0.1 \%$ bovine serum albumin

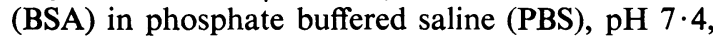
overnight at $4^{\circ} \mathrm{C}$ in collagen-coated tubes, and then the tubes were washed 3 times in PBS. $2 \cdot 7 \mu \mathrm{g}$ of ${ }^{125}$ I-labelled antirat IgG or IgM was added with $500 \mu \mathrm{l}$ of $0.1 \%$ BSA in PBS and incubated at room temperature for 4 hours. After a further 3 washes in PBS the tubes were counted on an LKB Ultro gamma spectrometer.

Control tubes containing no serum were included in each assay and the results corrected for nonspecific binding. Results were expressed as milligrams of antigen-specific IgG or IgM antibody per litre of serum.

Results for groups of rats were compared by the two-tailed Mann-Witney $U$ test (Siegal, 1956).

IgG antiglobulins were measured by the method of Hay et al. (1975) and expressed as mg/litre serum.

\section{Results}

\section{INCIDENCE AND COURSE OF ARTHRITIS}

An inflammatory, acute or chronic, arthritis developed in $76 \%$ of rats injected intradermally with native bovine type II collagen in either CFA or ICFA (Table 1). The onset of arthritis was typified by gross swelling and erythema involving 1 or more hind limbs, particularly the ankle, tarsal, and metatarsal joints (Fig. 1). The forefeet became similarly involved in a few rats. In 20 out of 37 rats the arthritis involved more than 1 limb.

The onset of arthritis occurred between 10 and 15 days after the initial injection. Of the 28 rats with arthritis, the swelling subsided in 4 to 30 days after onset in 12, the swelling persisted for longer than 42 days and was considered a chronic arthritis in 14, and 2 rats died under anaesthesia early in the
Table 1 Incidence of arthritis

\begin{tabular}{lll}
\hline $\begin{array}{l}\text { Rats injected with } \\
\text { native bovine type II } \\
\text { collagen in: }\end{array}$ & $\begin{array}{l}\text { Number of rats with: } \\
\text { Arthritis at } \\
\text { any stage }\end{array}$ & $\begin{array}{l}\text { Chronic } \\
\text { arthritis }\end{array}$ \\
\hline (a) ICFA & $21 / 28$ & $11 / 22$ \\
(b) CFA & $7 / 9$ & $3 / 9$ \\
Total & $28 / 37$ & $14 / 31$ \\
Per cent. & 76 & 45 \\
\hline
\end{tabular}

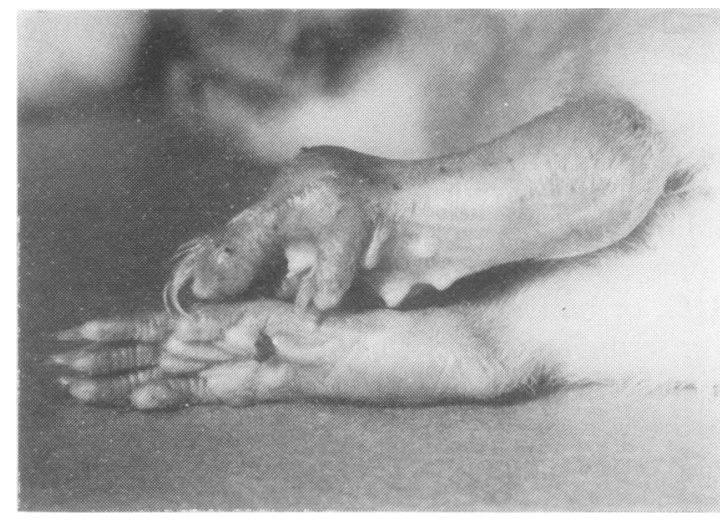

Fig. 1 Involvement of the tarsal, metatarsophalangeal, and interphalangeal joints of the left hind limb of a rat with chronic arthritis

experiment. Eventual clinical ankylosis of the involved joints occurred and was also noticed to involve the knee joints in a few rats.

Occasionally the distal region of the tail became swollen. The swelling appeared to be related to the region of the cartilaginous endplates. In a number of rats one or both ears became erythematous and $\bar{\sigma}$ swollen, and although this was more marked in some of the arthritic rats it also occurred in nonarthritic 8 rats. No obvious involvement of the eyes or nose was seen. Injection sites became ulcerated in rats injected ㅇ with CFA, but only mild reaction was seen in rats $>$ injected with ICFA, though the sites were palpable as thickened areas throughout the experiment. Some N weight loss was apparent in arthritic rats up to 28 \% days after injection, but weight gain appeared $\tilde{N}$ normal after this time.

No arthritis was induced by the regimens shown in Table 2, and no lesions in the ears or tail were 0 observed. Therefore arthritis was induced only by the intradermal injection of native type II collagen $\stackrel{\oplus}{+}$ emulsified in adjuvant. Thus native type II collagen 70 adjuvant, and the intradermal route were necessary for the production of arthritis.

HUMORAL IMMUNITY TO COLLAGEN Antibody levels to collagen were closely followed in those rats injected with native type II collagen 
Table 2 Regimens failing to induce arthritis

\begin{tabular}{lllc}
\hline Antigen used & Adjuvant & $\begin{array}{l}\text { Injection } \\
\text { site }\end{array}$ & $\begin{array}{l}\text { No. of } \\
\text { rats }\end{array}$ \\
\hline Native bovine type I collagen & ICFA & ID & 11 \\
Native bovine type I collagen & CFA & ID & 4 \\
Native bovine type I collagen & CFA & SC & 3 \\
Native bovine type II collagen & None & ID & 4 \\
Native bovine type II collagen & CFA & SC & 3 \\
Denatured bovine type II collagen ICFA & ID & 11 \\
Rabbit IgG & ICFA & ID & 6 \\
Rabbit IgG & CFA & ID & 9 \\
None & ICFA & ID & 4 \\
None & CFA & ID & 5 \\
\hline
\end{tabular}

ID =intradermal. $\quad \mathrm{SC}=$ subcutaneous

in ICFA and boosted by intraperitoneal injection with native type II collagen after 21 days. IgM antibodies to native bovine type II collagen were present when measured 7 days after primary immunisation and rose to a peak 8 days later. The antibody levels returned to normal approximately 42 days after injection. IgM antibodies to native bovine type II collagen were significantly higher in those rats which developed acute or chronic arthritis than in rats that never developed arthritis (Fig. 2). However, they returned to near normal levels while the arthritis persisted. There was no significant difference between IgM levels in rats with acute or chronic arthritis.

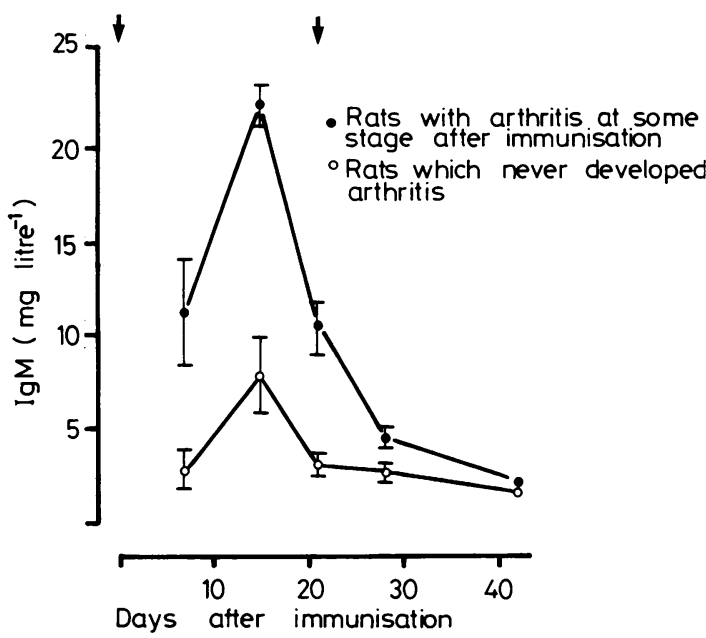

Fig. 2 IgM antibody levels to native bovine type II collagen in rats injected with native type II collagen in ICFA with a 21-day boost of collagen alone. Arthritic rat values were significantly different from non-arthritic rats as follows: Day 7, $P=0.048$; day 15, $P<<0.002$; day 21, $P<0.002 ;$ day 28, $P=0.02 ;$ day $42, P>0 \cdot 1$, not significant. Results expressed as mean \pm standard error of the mean and days of primary and booster injection are arrowed in all figures.
IgG antibodies to native bovine type II collagen were also present in these rats and reached maximum levels 21 days after primary immunisation. The levels gradually declined though high levels were still present 56 days after primary injection. Similar IgG antibody levels were present in 6 rats which were not boosted. Rats with acute or chronic arthritis had significantly higher levels of IgG antibody to native bovine type II collagen than rats without arthritis although again there was no significant difference between IgG levels in acute and chronic arthritic rats (Fig. 3).

IgM and IgG antibodies to native bovine type II collagen in rats injected with native type II collagen alone were very low or absent, as were IgG antibody levels to type II collagen in rats injected with adjuvant alone (Table 3).

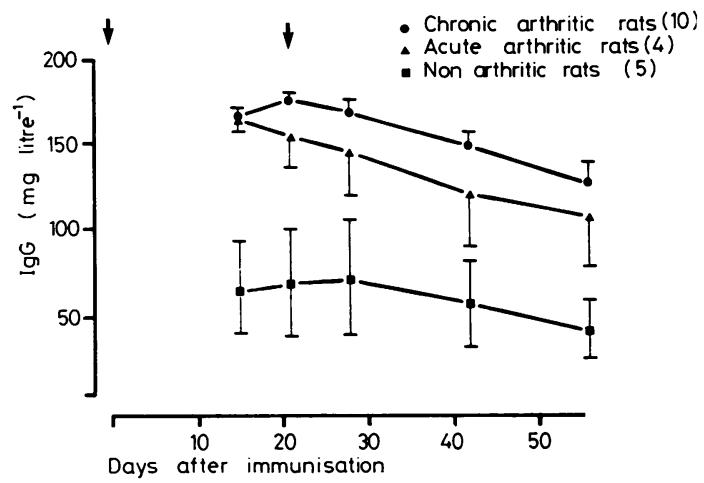

Fig. 3 IgG antibody levels to native bovine type II collagen in rats injected with native bovine type II collagen in ICFA with 21 day boost of collagen alone. Acute and chronic rat values were significantly different from nonarthritic rats as follows; day 15, $P<0.002$; day 21, $P<0.02$; day 28, $P<0.05$; day 42, $P<0.02$; day $56, P<0.02$.

Table 3 Collagen antibody levels in rats immunised with native bovine type II collagen alone or with adjuvant and buffer alone

\begin{tabular}{|c|c|c|c|}
\hline \multirow{2}{*}{$\begin{array}{l}\text { Days } \\
\text { after } \\
\text { injection }\end{array}$} & \multirow[t]{2}{*}{ Rats immunised with: } & \multicolumn{2}{|c|}{ Antibody levels } \\
\hline & & $\begin{array}{l}\text { IgM } \\
\text { (mg/litre) }\end{array}$ & $\begin{array}{l}\text { IgG } \\
\text { (mg/litre) }\end{array}$ \\
\hline $\begin{array}{l}10 \\
20 \\
28 \\
42 \\
55 \\
21 \\
42 \\
63 \\
21 \\
42 \\
63\end{array}$ & $\begin{array}{l}\text { ICFA + buffer } \\
\text { CFA + buffer }\end{array}$ & $\begin{array}{l}3 \cdot 9 \pm 0.4 \mathrm{a} \\
3 \cdot 7 \pm 0.6 \\
3 \cdot 4 \pm 0.6 \\
2 \cdot 8 \pm 0.2 \\
\text { NT } \\
\text { NT } \\
\text { NT } \\
\text { NT } \\
\text { NT } \\
\text { NT } \\
\text { NT }\end{array}$ & $\begin{array}{l}3 \cdot 3 \pm 0 \cdot 5 \\
3 \cdot 9 \pm 0 \cdot 5 \\
5 \cdot 6 \pm 0 \cdot 8 \\
5 \cdot 9 \pm 0 \cdot 6 \\
5 \cdot 4 \pm 0 \cdot 6 \\
0.9 \pm 0 \cdot 1 \\
1 \cdot 6 \pm 0 \cdot 8 \\
1 \cdot 2 \pm 0 \cdot 3 \\
1 \cdot 1 \pm 0 \cdot 2 \\
1 \cdot 8 \pm 0.5 \\
2.4 \pm 0.6\end{array}$ \\
\hline
\end{tabular}

$\mathrm{NT}=$ Not tested. $\quad a=$ Mean \pm standard error of the mean $(\mathrm{SEM})$. 
Rats injected with native bovine type II collagen were tested for antibodies against denatured bovine type II collagen as they share an antigenic determinant (Furthmayr and Timpl, 1976), The denatured bovine type II collagen determinant accounted for $50-60 \%$ of the measured immunological antigenicity of native bovine type II collagen (c.f. Figs. 3 and 4), which confirmed previous studies (Furthmayr and Timpl, 1976; Clague et al., 1979a).

Rats injected intradermally with native bovine type I collagen emulsified in CFA produced high levels of IgG antibodies to this antigen (Fig. 5), which were equivalent to the responses obtained with native type II collagen when the latter are analysed as 1 group. However, native bovine type I collagen emulsified in ICFA produced a very low level of IgG antibody to this antigen, being only slightly higher than that found with normal rat sera in this

Chronic arthritic rats (10)

- Acute arthritic rats (4)

- Non-arthritic rats (5)

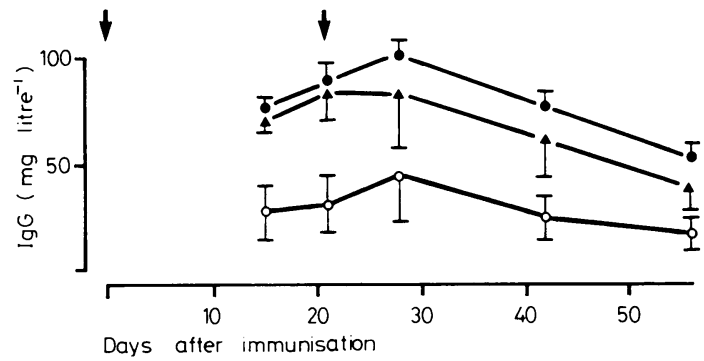

Fig. 4 IgG antibody levels to denatured bovine type II collagen in rats injected with native bovine type II collagen in ICFA with 21 day boost of native collagen alone

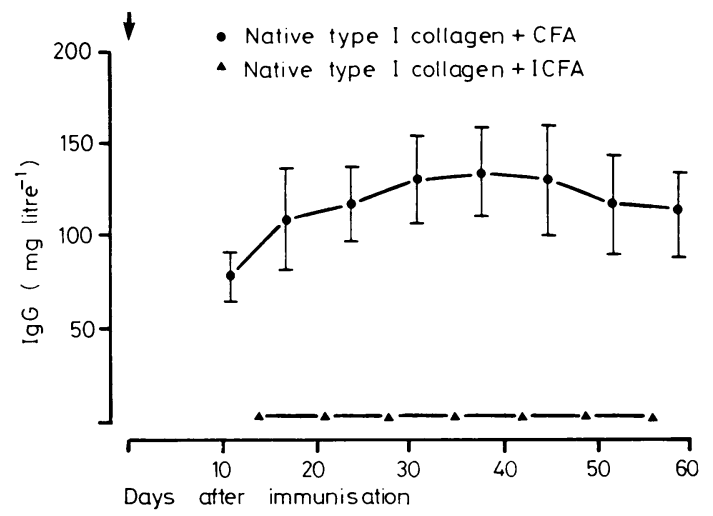

Fig. 5 IgG antibody levels to native bovine type I collagen in rats injected with native bovine type I collagen in ICFA or CFA.
Table 4 IgG antibody levels to rabbit IgG in sera from arthritic and nonarthritic rats using the method of Hay et al. (1975).

\begin{tabular}{|c|c|c|c|}
\hline \multirow[t]{2}{*}{$\begin{array}{l}\text { Days after } \\
\text { injection }\end{array}$} & \multirow[t]{2}{*}{ Rats immunised to: } & \multirow{2}{*}{$\begin{array}{l}\text { Arthritic } \\
\text { rats } \\
\overrightarrow{\operatorname{Ig} G(m g / \text { litre })}\end{array}$} & \multirow{2}{*}{$\begin{array}{l}\begin{array}{l}\text { Nonarthritic } \\
\text { rats }\end{array} \\
\lg G(\mathrm{mg} / \text { litre })\end{array}$} \\
\hline & & & \\
\hline 15 & $\begin{array}{l}\text { Native bovine type } \\
\text { II collagen }\end{array}$ & $0 \cdot 5 \pm 0.08 \mathrm{a}$ & $0.5 \pm 0.08$ \\
\hline 28 & $\begin{array}{l}\text { Native bovine type } \\
\text { II collagen }\end{array}$ & $0.4 \pm 0.04$ & $0.4 \pm 0.02$ \\
\hline 56 & $\begin{array}{l}\text { Native bovine type } \\
\text { II collagen }\end{array}$ & $0.4 \pm 0.04$ & $0.3 \pm 0.04$ \\
\hline 14 & $\begin{array}{l}\text { Native bovine type } \\
\text { I collagen }\end{array}$ & & $0.4 \pm 0.04$ \\
\hline 28 & $\begin{array}{l}\text { Native bovine type } \\
\text { I collagen }\end{array}$ & & $0.5 \pm 0.09$ \\
\hline 56 & $\begin{array}{l}\text { Native bovine type } \\
\text { I collagen }\end{array}$ & & $0.5 \pm 0.06$ \\
\hline 14 & Rabbit IgG & & $3 \cdot 4 \pm 0 \cdot 15$ \\
\hline 一 & Unimmunised & & $0.5 \pm 0.04$ \\
\hline
\end{tabular}

$\mathbf{a}=$ Mean \pm SEM

assay. Thus the immunogenicity of type I collagen differed from the immunogencity of type II collagen when emulsified in ICFA but did not differ emulsified in CFA.

No difference in IgG antibody levels to rabbit $\mathrm{IgG}$, that is, antiglobulin antibody, was found in arthritic rats injected with native bovine type II collagen when compared with nonarthritic rats injected with the same antigen, with unimmunised rats, or rats injected with bovine type I collagen (Table 4).

\section{Discussion}

A chronic inflammatory arthritis was induced in approximately $45 \%$ of rats by the intradermal injection of native bovine type II collagen emulsified in Freund's complete or incomplete adjuvant. This finding is in agreement with Trentham et al. (1977), who obtained a $41 \%$ incidence of arthritis in rats using native chick, human, and rat type II collagens. In these studies we used outbred Sprague Dawley rats but have recently induced arthritis in inbred Black-Hooded rats and inbred DA rats. Thus, with inclusion of the work of Trentham et al. (1977), arthritis has been induced in all of the 5 different rat strains tested.

The arthritis mainly affected 1 or both hind limbs, especially the tarsal region, but involvement of major joints and other joints in the hind limbs and fore limbs also occurred. Thus, it appears to be a true polyarthritis. Systemic involvement showed as mild weight loss, ear lesions, and tail involvement, though these were not directly associated with the severity of the arthritis.

We have not conducted a systematic histological 
study, but preliminary findings confirm the report by Trentham et al. (1977) of the presence of a proliferative synovitis accompanying an erosive arthritis and periosteitis.

The arthritis appears to resemble adjuvant disease in the rat (Pearson and Wood, 1963) which is induced by the injection of supplemented CFA into the foot pad or base of the tail. A polyarthritis develops 14-21 days later, affecting mainly the tarsal region in the hind limbs, but other joints may be involved. Nodular lesions occur on the ears, and the tail also becomes nodular, the condition leading to ankylosis. These lesions resemble the lesions found in type II collagen-induced arthritis but appear more severe. In type II collagen-induced arthritis the arthritis together with the ear and tail lesions may be related to immunity to type II collagen, as this collagen is found in the articular cartilage (Miller and Matukas, 1974), the ear, and intervertebral discs (Eyre and Muir, 1976). However, in adjuvant disease a different mechanism appears to be involved, since we have found no immunity to native rat type II collagen in sera from rats with adjuvant disease on days 17 and 49 (personal observations).

The presence of mycobacteria as in complete Freund's adjuvant, was not essential for the production of the arthritis, which was induced by native type II collagen in Freund's incomplete adjuvant. The use of adjuvant appears to be necessary to enhance the immune response to native type II collagen, as this antigen alone, when injected intradermally, produced a low antibody response and no arthritis.

We have demonstrated a greater IgM and IgG response to native bovine type II collagen in rats which developed arthritis as compared with nonarthritic rats. The IgM response was short-lived in comparison with the $\operatorname{IgG}$ response which was prolonged. These findings suggest a role for these antibodies in the production of arthritis in this rat model.

IgG levels to native bovine type II collagen were similar in acute and chronic arthritic rats, suggesting that another mechanism may be important in perpetuating the arthritis. Cell-mediated immunity to native type II collagen has been demonstrated by Trentham et al. (1978) in rats injected with this antigen, but it is unclear whether higher levels of cellular sensitivity to the antigen are related to the chronicity of the arthritis.

The involvement of other mechanisms such as immune complexes in the initiation and/or perpetuation of collagen-induced arthritis have not been investigated so far.

The native type II collagen was extracted by pepsin solubilisation, which removes the nonhelical (telo- peptide) region of the molecule but leaves the helical region intact (Miller, 1972). The helical region of native collagen has 2 major antigenic determinants (Furthmayr and Timpl, 1976). The first determinant is conformational-dependent and unique to the native molecule, while the second is a sequential determinant still present when the collagen is denatured. Native bovine type I collagen differs from native bovine type II collagen in its immunogenicity, as unlike native type II collagen it elicits only a poor IgG antibody response when emulsified in ICFA and injected intradermally.

These findings suggest that there may be a determinant present in native type II collagen which expresses an intrinsic adjuvanticity. Further studies are in progress to investigate whether the intrinsic adjuvanticity resides in the conformational or sequential determinants of the type II molecule. The conformational determinant of native type II collagen appears essential for the induction of arthritis in this rat model, as denatured type II collagen did not induce arthritis.

This model may be an example of an experimental arthritis induced by an autoimmune response to native type II collagen. It has several advantages over previously described experimental models of arthritis. Compared with adjuvant disease in the rat the use of a well-defined antigen which is a component of normal joint tissue lends itself to closely defined immunological studies. The induction of chronic synovitis in the rabbit (Dumonde and Glynn, 1962) or in the mouse (Brackertz et al., 1977a) requires the use of a foreign antigen which after prior immunisation with complete Freund's adjuvant has to be injected intra-articularly.

Previous studies have demonstrated a positive correlation between the antibody titres and the degree of chronic synovitis in the rabbit model (Cooke and Jasin, 1972), and a higher responder state to the antigen was found in mice susceptible to arthritis induced by methylated-bovine serum albumin (Brackertz et al., 1977b). These observations all suggest that a good humoral response to an antigen is important in antigen-induced arthritis.

A further interesting observation is the occurrence of antibodies to native type II collagen in patients with rheumatoid arthritis (Andriopoulos et al., 1976; Clague et al., 1979b), though the significance of these antibodies in man is at present unclear.

Further studies are in progress to delineate which features of the immunological response to native type II collagen are important in the induction and perpetuation of the arthritis.

We are grateful to Miss Jacqueline Weiss and Dr R. Brown for analysis of the collagen types and for advice on their 
preparation. We thank Miss Linda Hunt (Faculty of Medicine Computational Group) for statistical advice, Mrs Doreen Ward for typing the manuscript, and Mrs S. Roe (Department of Medical Illustrations) for preparing the figures.

The work was supported by grants from the Arthritis and Rheumatism Council, Medical Research Council, and the North-west Regional Hospital Board.

\section{References}

Andriopoulos, N. A., Mestecky, J., Miller, E. J., and Bradley, E. L. (1976). Antibodies to native and denatured collagens in sera of patients with rheumatoid arthritis. Arthritis and Rheumatism, 19, 613-617.

Bitter, T., and Muir, H. M. (1962). A modified uronic acid carbazole reaction. Analytical Biochemistry, 4, 330-334.

Brackertz, D., Mitchell, G. F., and Mackay, I. R. (1977a). Antigen-induced arthritis in the mouse. I. Induction of arthrit is in various strains of mice. Arthritis and Rheumatism, 20, 841-850.

Brackertz, D., Mitchell, G. F., Vadas, M. A., Mackay, I. R., and Miller, J. F. A. P. (1977b). Studies on antigenarthritis in mice. II. Immunologic correlates of arthritis susceptibility in mice. Journal of Immunology, 118, 16391644.

Clague, R. B., Brown, R. A., Weiss, J. B., and Holt, P. J. L. (1979a). Solid-phase radioimmunoassay for the detection of antibodies to collagen. Journal of Immunological Methods (in press).

Clague, R. B., Shaw, M. J., and Holt, P. J. L. (1979b). Incidence of serum IgG antibodies to native type $I$ and type II collagen in patients with inflammatory arthritis. Annals of the Rheumatic Diseases (in press).

Cooke, T. D., and Jasin, H. E. (1972). The pathogenesis of chronic inflammation in experimental antigen-induced arthritis. I. The role of antigen on the local immune response. Arthritis and Rheumatism, 15, 327-337.

Dumonde, D. C., and Glynn, L. E. (1962). The production of arthritis in rabbits by an immunological reaction to fibrin. British Journal of Experimental Pathology, 43, 373-383.
Eyre, D. R., and Muir, H. (1976). Type I and II collagens in intervertebral disc. Interchanging radial distribution in annulus fibrosus. Biochemical Journal, 157, 267-270.

Furthmayr, H., and Timpl, R. (1976). Immunochemistry of collagens and procollagens. International Review of Connective Tissue Research, 7, 61-99.

Hay, F. C., Nineham, L. J., and Roitt, I. M. (1975). Routine assay for detection of IgG and IgM antiglobulins in seronegative and seropositive rheumatoid arthritis. British Medical Journal, 3, 203-204.

Hudson, L., and Hay, F. C. (1976). Practical Immunology, p. 162. Blackwell Scientific Publications: Oxford.

Jackson, D. S., and Cleary, E. G. (1967). In Methods of Biochemical Analysis, vol. 15, pp. 32-33. Edited by D. Glick. Interscience Publishers: London.

Miller, E. J. (1972). Structural studies on cartilage collagen employing limited cleavage and solubilization with pepsin. Biochemistry, 11, 4903-4909.

Miller, E. J., and Matukas, V. J. (1974). Biosynthesis of collagen. The biochemist's view. Federation Proceedings, 33, 1197-1204.

Pearson, C. M., and Wood, F. D. (1963). Studies of arthritis and other lessions induced by the injection of mycobacterial adjuvant. VII. Pathologic details of the arthritis and spondylitis. American Journal of Pathology, 42, 73-95.

Siegal, S. (1956). Non-parametric Statistics for the Behavioural Sciences. International Student Edition. McGraw-Hill Kogakusha.

Trentham, D. E., Townes, A. S., and Kang, A. H. (1977). Autoimmunity to type II collagen: an experimental model of arthritis. Journal of Experimental Medicine, 146, 857-867.

Trentham, D. E., Townes, A. S., Kang, A. H., and David, J. R. (1978). Humoral and cellular sensitivity to collagen in type II collagen-induced arthritis in rats. Journal of Clinical Investigation, 61, 89-96.

Trelstad, R. L., Rubin, D., and Gross, J. (1977). Osteogenesis imperfecta congenita: evidence for a generalised molecular disorder of collagen. Laboratory Investigation, 36, 501-508. 